\title{
Study on Leaf Spring Torsion with Elastic Large Deformation
}

\author{
Su Xunwen ${ }^{1, *}$ and Zhu Dongmei ${ }^{2}$
}

\author{
${ }^{1}$ School of Technology, Beijing Forestry University, Beijing, 100083, China; ${ }^{2}$ School of Mechanical Engineering, Uni- \\ versity of Science and Technology Beijing, Beijing 100083, China
}

\begin{abstract}
The aim of this study is to show the relationship of elastic large deformation between torque and torsional angle for a bar with rectangular cross section. The formula about torque and torsional angle is modified by numerical analysis and experimental verification. High order item of torsional angle is added to the traditional formula, based on different boundary condition, which was set to zero before in the textbook. Using improved formula higher accuracy loading will be gotten when a leaf spring is twisted to elastic large deformation. Two types of leaf springs are used with depth of $6.8 \mathrm{~mm}$ and $7.7 \mathrm{~mm}$ with the same width of $100 \mathrm{~mm}$. The leaf springs are analyzed by finite element software of ANSYS with unit of SOLID 45 . They are also tested by mechanical torsional loading device, with linear loading from 0 to $830 \mathrm{~N}$.m or 0 to $560 \mathrm{~N} . \mathrm{m}$ respectively. Both theoretical analysis and experimental results show that, there are some nonlinear characteristics when leaf springs with elastic large deformation. With comparison to linear fitting and cubic curve fitting, the linear fitting has larger error than cubic curve fitting. The cubic curve fitting can improve accuracy about 2 orders. In order to improve precision of leaf spring loading, the high-order curve should be used.
\end{abstract}

Keywords: ANSYS, leaf spring, rectangular section, torsion.

\section{INTRODUCTION}

The leaf spring is an important member of damping and bearing for a vehicle. As it can bear larger torque, sometimes, it is used for twist loading in mechanical loading device. Elastic leaf springs can provide leverage for displacement reduction mechanisms, which is widely used because it has high positioning repeatability and linear motion. Now it can provide precise motion of nanometer displacement [1].

Since a leaf spring has rectangular section, when twisted, the section will not satisfy the plane cross- section assumption. And the cross section will be warping. In engineering, when a member with rectangular cross section is twisted, the empirical formulas will be used as below [2],

$$
\begin{aligned}
& \tau_{\text {max }}=\frac{T}{\alpha h b^{2}} \\
& \tau_{1}=\gamma \tau_{\max } \\
& \varphi=\frac{T l}{G \beta h b^{3}}
\end{aligned}
$$

where, $\tau_{\max }$ is the shear stress of the middle point of the long side of the cross section, $\tau_{1}$ is the shear stress of the middle point of the short side of the cross section, $T$ is the torque loading; $l$ is effective length of the leaf spring; $G$ is a shear modulus of elasticity; $\alpha, \beta, \gamma$ is value related with width $b$ and height $h$ of the rectangular section.

Generally, leaf springs are mainly used for supporting loading, so the torsional angle is very small. When the deformation is small, the precision of this formula can satisfy engineering, however when the deformation is large, the precision maybe can't satisfy engineering. For example, when a leaf spring is used for torque loading, deformation will be large, and the precision will be too low.

Kobelev [3] discussed basic solutions for creep with nonlinearity, and exact analytical expression for torsion and bending creep of rods was derived, the formulas could do good to calculation of leaf spring and other twisted rods or springs. Torque and bending moment were used as functions of time during the period of relaxation. However, the large deformation of leaf spring was not discussed.

Actuator loading technology has become an important technology to test the performance and improve the parameters of actuator. So far, two forms of loading methods are widely used in industry fields: One method is mechanical loading which is realized by loading mechanical medias, such as weights, inertia plates, leaf spring and so on; the other method is electro-hydraulic loading which includes roll loading realized by adopting servo valve-motor, and linear loading realized by adopting the servo valve-cylinder. By virtue of simple mechanical structure and lower cost, the mechanical loading as core of the leaf spring is popular, and it has become the main mechanical loading method in today's industry application [4-6].

However, the leaf spring linear loading has some disadvantages of larger error and lower precision, so its applica- 
tion is greatly restricted. As we know, according to the theory of elasticity, the relationship between loading torque and leaf spring's torsion angle should be linear, however, there are somewhat conflicts between the theoretical analysis and the real experiment results [7-9]. Generally, in order to simplify the calculation, the boundary condition is set as zero. It may be right when the torsion angle is small, but when the larger deformation exists in the leaf spring, it may be not true.

In this paper, it is assumed that the boundary condition of the system is nonzero which is set as the high-order term about torsion angle. Then the new formula describing the relationship between torque and torsion angle is obtained. The Finite Element Analysis (FEA) software of ANSYS is used to verify this formula. An experimental device is also used to validate it. Both the ANSYS analysis and the experiment results indicate that three-order curve is much more precise than the linear curve. That means the assumption of nonzero boundary condition is correct. So it is better that the higher order curve is based for the leaf spring torsion of the actuator loading.

\section{TORSION OF RECTANGULAR CROSS SECTION BAR}

A leaf spring has a rectangular section. If a bar with rectangular cross section, it will not satisfy the plane assumption when twisted by a torque. The cross section will become warpage. The formula derived based on plane cross section assumption will no longer be applicable [10-13]. The problem is discussed in the elasticity [6].

As shown in Fig. (1), the rectangle is a section of a rod member. Provided its length of long side and short side, is a and $\mathrm{b}$ respectively, the coordinate system $\mathrm{xOy}$ is established over section centroid $\mathrm{O}$, and $\mathrm{z}$-axis is perpendicular to the $\mathrm{xy}$ plane. Torques $\mathrm{M}$ will be applied at both ends of the bar.

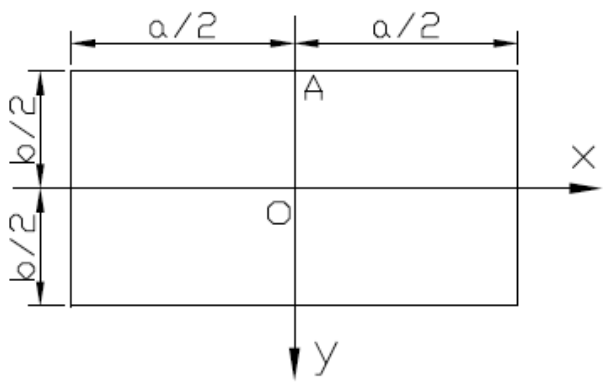

Fig. (1). Rectangular cross section.

Using the method of membrane analogy, suppose the stress function is $\varphi(x, y)$, and $a / b$ is a large value based on elasticity. The stress function has noting on $\mathrm{x}$ in most of the cross section. Let

$\frac{\partial \varphi}{\partial x}=0, \frac{\partial \varphi}{\partial y}=\frac{d \varphi}{d y}$

So $x$ direction shear stress is,

$\tau_{z x}=\frac{\partial \varphi}{\partial y}=\frac{d \varphi}{d y}$

And $y$ direction shear stress is $\tau_{z y}=\frac{\partial \varphi}{\partial x}=0$

Introduce the Laplace arithmetic operator $\nabla^{2}$, and torsion angle $k$

$\nabla^{2}=\frac{\partial^{2}}{\partial x^{2}}+\frac{\partial^{2}}{\partial y^{2}}+\frac{\partial^{2}}{\partial z^{2}}$

Then the stress function should satisfy,

$\nabla^{2} \varphi=-2 G k$

Boundary conditions are,

$(\varphi)_{x= \pm \frac{a}{2}}=0,(\varphi)_{y= \pm \frac{b}{2}}=0$

We get the stress function as below [14],

$\varphi=G k\left(\frac{b^{2}}{4}-y^{2}\right)$

Which is satisfied with boundary conditions of Eq. (9).

If the cross section is arbitrary $a / b$, that is the value of is arbitrary, then the stress function is [14]

$\varphi=G k\left(\frac{b^{2}}{4}-y^{2}\right)+F(x, y)$

In which, $F$ is a correction function. Let $F$ be an infinite series,

$F=\sum_{m=1,3,5 \cdots}^{\infty} A_{m} \operatorname{ch} \frac{m \pi x}{b} \cos \frac{m \pi y}{b}$

So,

$\varphi=G k\left[\frac{b^{2}}{4}-y^{2}-\frac{8 b^{2}}{\pi^{3}} \sum_{m=1,3,5}^{\infty} \frac{(-1)^{\frac{m-1}{2}} \operatorname{ch} \frac{m \pi x}{b} \cos \frac{m \pi y}{b}}{m^{3} \operatorname{ch} \frac{m \pi a}{2 b}}\right]$

And the stress function $\varphi$ should satisfy the boundary conditions of Eq.(9).

From Eq.(5) and Eq.(7)., we can see that, the shear stress is a first derivative of stress function $\varphi(x, y)$, then adding a const to the stress function will not affect the value of shear stress. In engineering, for ease of calculation, regularly let the stress function be zero $(\varphi)=0$ [14]. From Eq.(13), when $x$ and $y$ are certain, the relationship between stress and torsion angle $k$ is linear, that may ignore the high order item of torsion angle $k$. So without loss of generality, add a constant item $\sum_{n=1}^{t} c_{n} k^{n}$ to Eq.(13), where $c_{n}$ is a coefficient.

Then Eq.(13) changes to,

$\varphi=G k\left[\frac{b^{2}}{4}-y^{2}-\frac{8 b^{2}}{\pi^{3}} \sum_{m=1,3,5 \cdots}^{\infty} \frac{(-1)^{\frac{m-1}{2}} \operatorname{ch} \frac{m \pi x}{b} \cos \frac{m \pi y}{b}}{m^{3} \operatorname{ch} \frac{m \pi a}{2 b}}\right]+\sum_{n=1}^{t} c_{n} k^{n}$ 


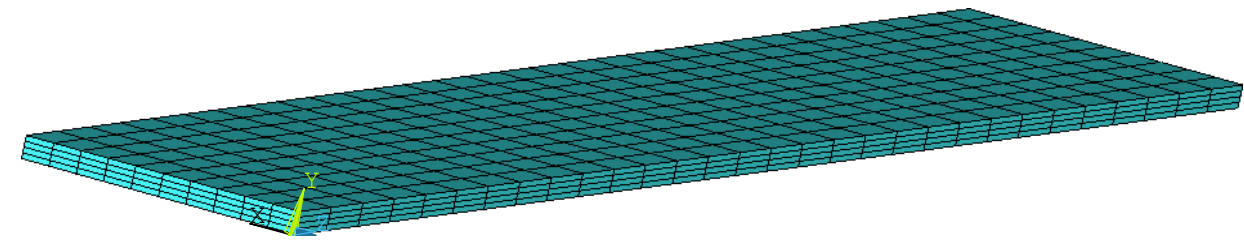

Fig. (2). Meshing of the leaf spring.

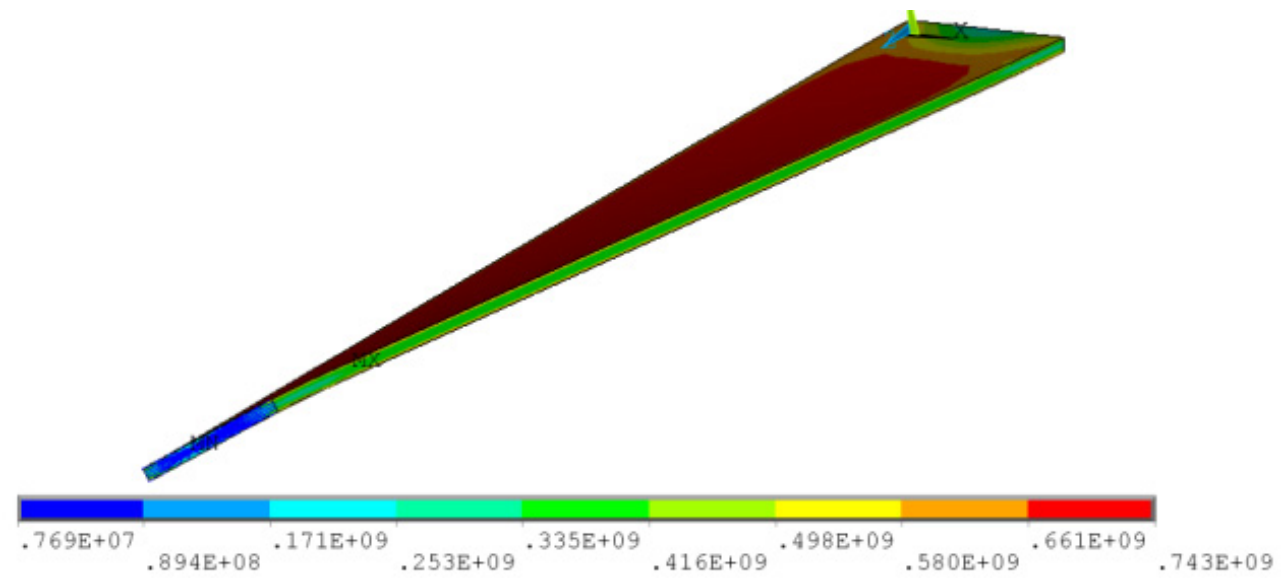

Fig. (3). Stress of the leaf spring torsion.

As the moment of couple is,

$M=2 \iint \varphi d x d y$

Then

$M=G k a b^{3}\left[\frac{1}{3}-\frac{64}{\pi^{5}} \frac{b}{a} \sum_{m=1,3,5 \ldots}^{\infty} \frac{t h \frac{m \pi a}{2 b}}{m^{5}}\right]+\sum_{n=1}^{t} c_{n} a b k^{n}$

Let

$d_{n}=c_{n} a b$

Simply Eq.(14), let,

$\beta=\left[\frac{1}{3}-\frac{64}{\pi^{5}} \frac{b}{a} \sum_{m=1,3,5 \ldots}^{\infty} \frac{t h \frac{m \pi a}{2 b}}{m^{5}}\right]$

Then Eq.(13) becomes,

$M=G k a b^{3} \beta+\sum_{n=1}^{t} d_{n} k^{n}$

From Eq.(19), we can obtain that given torsional angle $k$, the torque $M$ will be gotten. Since torsional angle is easy to measure, when the coefficients are certain, the higher accuracy torque $M$ will be is certain.

\section{ANSYS ANALYSIS OF ELASTIC LARGE DEFOR- MATION}

The models established using ANSYS are according to the experimental members, which will be used in the next section of this paper. Two types of leaf springs are used. One's depth is $6.8 \mathrm{~mm}$, the other is $7.7 \mathrm{~mm}$. Both of them have the same length of $1000 \mathrm{~mm}$, and the same length of the long side of the cross section. Suppose the leaf spring with depth of $6.8 \mathrm{~mm}$ is $1 \#$, the other is $2 \#$.

The Finite Element Analysis software of ANSYS is chose, and the analysis method of nonlinear large deformation is used. Using SOLID 45 unit, and material parameters are module of elastic 206GPa, Poison's ratio 0.3. Since the length of a leaf spring is much larger than its cross-sectional dimension, mesh density along the section is greater than that of along the length during meshing. The meshing figure is shown as Fig. (2). After meshing, then one end of the spring is fixed, and the other end is loaded by torque. When 1 \# leaf spring is loaded with torque of $830 \mathrm{~N} . \mathrm{m}$, the stress cloud is shown as Fig. (3).

From Fig. (3), it can be seen that red color means the largest stress, and blue color means the least stress. When the leaf spring is twisted, inside of the leaf are even as the same except two ends of the leaf spring, which is because of fixing. As to the cross section, the stress along the long side of the cross section is larger than that of along the short side much more. The stresses of 4 corners of the cross section are equal to zero. Twist 2\# leaf spring, the same results will be gotten. All the phenomena are consistent with the results of experimental formulas. So simulation results are correct.

In order to get the relationship of torsional angle and torque, both the two types of leaf springs are loaded and analyzed. The torque is loaded from 0N.m to the setting value according to linear loading. Torques and torsional angles are recorded. Then the figure about torque-torsional angle is got, Fig. (4) is got from 1\# leaf spring with largest loading of 830 N.m, and Fig. (5) is for 2\# leaf spring with largest loading of $560 \mathrm{~N} . \mathrm{m}$. Both of the two leaf springs are clamped with effective length of $781 \mathrm{~mm}$. The results analyzed from ANSYS are fit. In Figs. (4 and $\mathbf{5}$ ) the red solid line is linear fitting and the blue solid line is 3 -order curve fitting. 


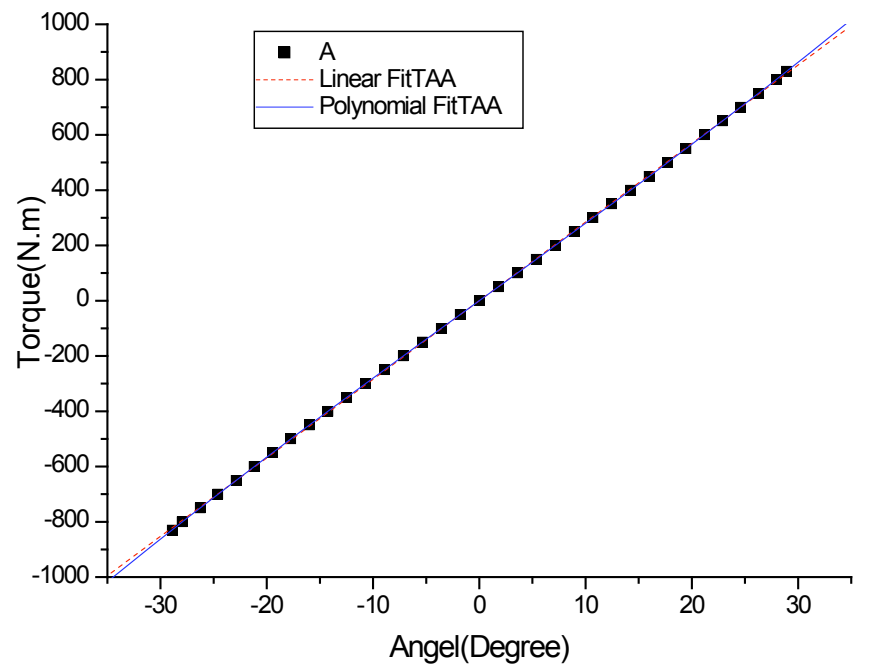

Fig. (4). 1\# leaf spring torque and torsional angle.

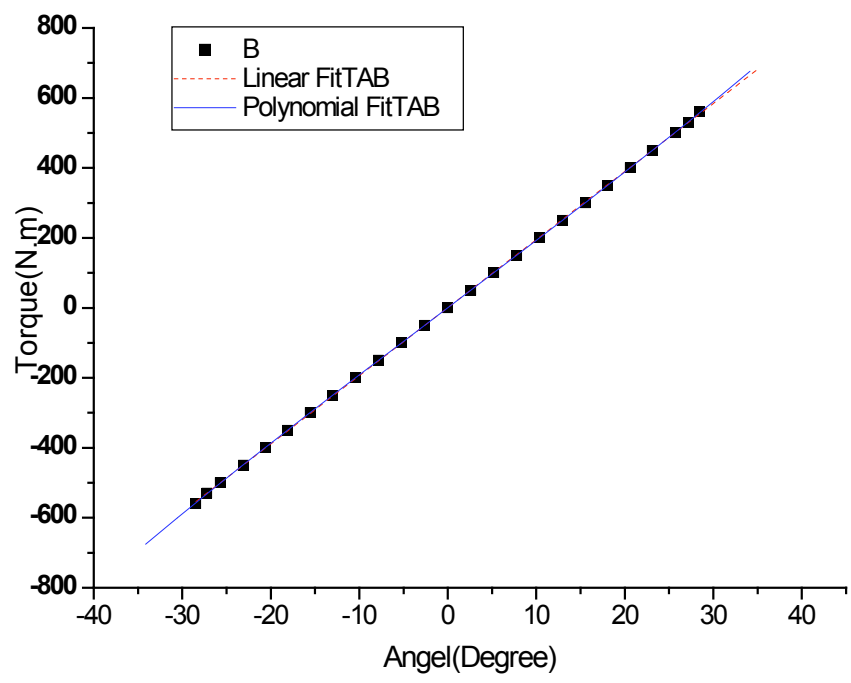

Fig. (5). 2\# leaf spring torque and torsional angle.

In order to show the fitting difference clearly, Figs. (6 and 7) show the enlarged details of the two kinds of fitting. From Figs. (4-7) it can be seen that red linear fit and blue cubic curve fit were similar, but not the same, especially with the increasing load the error increased. Leaf spring $1 \#$ and $2 \#$ have the same kind of torque and torsional angle relationship, and the geometry of the cross sections has smaller influences on the results. In order to compare the errors of the linear fitting and cubic curve fitting, Table $\mathbf{1}$ and $\mathbf{2}$ show the details in comparison data.

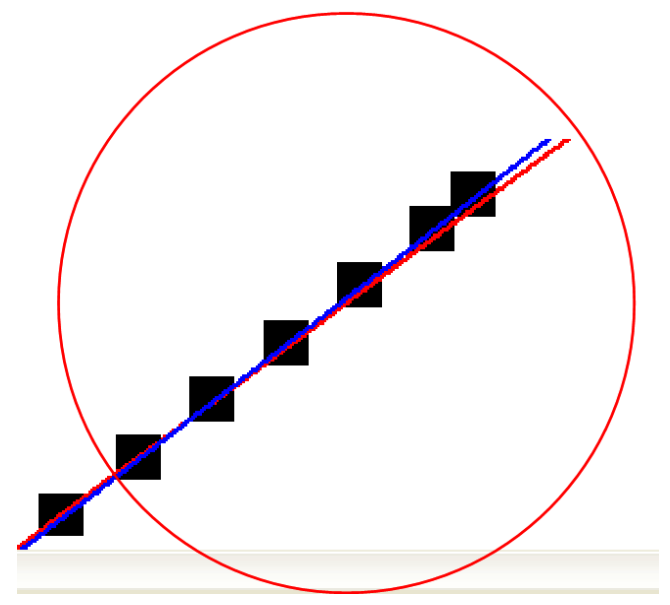

Fig. (6). Local enlarge image of Fig. (4).

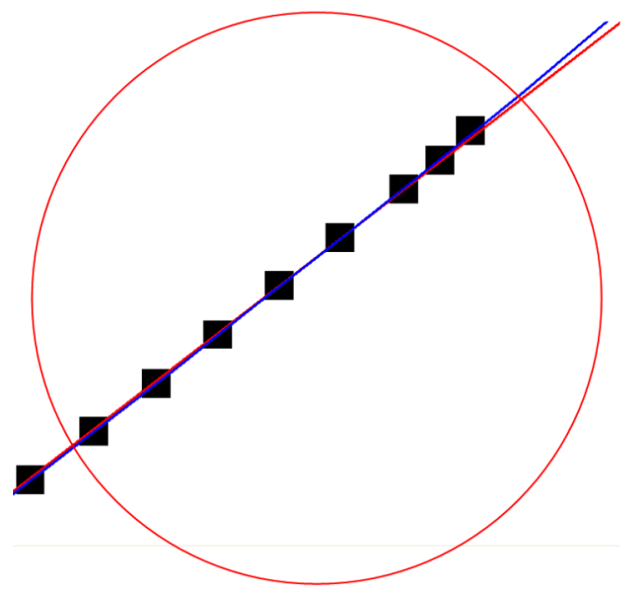

Fig. (7). Local enlarge image of Fig. (5).

From Table $\mathbf{1}$ and $\mathbf{2}$, it can be obtained that the cubic curve fitting has much smaller error, and the accuracy improvement is about 2 orders of magnitude. These results illustrate that when a rectangular cross section bar has elastic large deformation, torques and torsional angles are not linear. So if a leaf spring is used for loading, higher load curve used, more accurate torque loads will be got. Then the high order constant item of Eq.17 is very necessary.

\section{EXPERIMENT TEST AND ANALYSIS}

Fig. (6) is a schematic diagram of the leaf spring loading test rig. It consists of 2 stands, 1 leaf spring and a linked rotatable shaft, which can link the leaf spring and output shaft of a motor.

Table 1. Fitting errors for 1 \# leaf spring.

\begin{tabular}{|c|c|c|}
\hline & Curve-fit Equation & Error [\%] \\
\hline \hline Linear Fit & $M=28.42394 k$ & 1.4 \\
\hline Polynomial Fit (3-order) & $\mathrm{M}=1.13313 \times 10^{-14}+27.90787 \mathrm{k}-1.65393 \times 10^{-16} \mathrm{k}^{2}+9.35987 \times 10^{-4} \mathrm{k}^{3}$ & 0.33 \\
\hline Precision Improved [\%] & 424 \\
\hline
\end{tabular}

Note: $k$ is the torsion angle $/\left({ }^{\circ}\right), M$ is torque/(N.m). 
Table 2. Fitting errors for 2\# leaf spring.

\begin{tabular}{|c|c|c|}
\hline & Curve-fit Equation & Error [\%] \\
\hline \hline Linear Fit & $M=19.4613 k$ & 1.1 \\
\hline Polynomial Fit (3-order) & $\mathrm{M}=6.6069 \times 10^{-14}+19.1532 \mathrm{k}+5.456849 \times 10^{-4} \mathrm{k}^{3}$ & 0.43 \\
\hline Precision Improved [\%] & 256 & \\
\hline
\end{tabular}
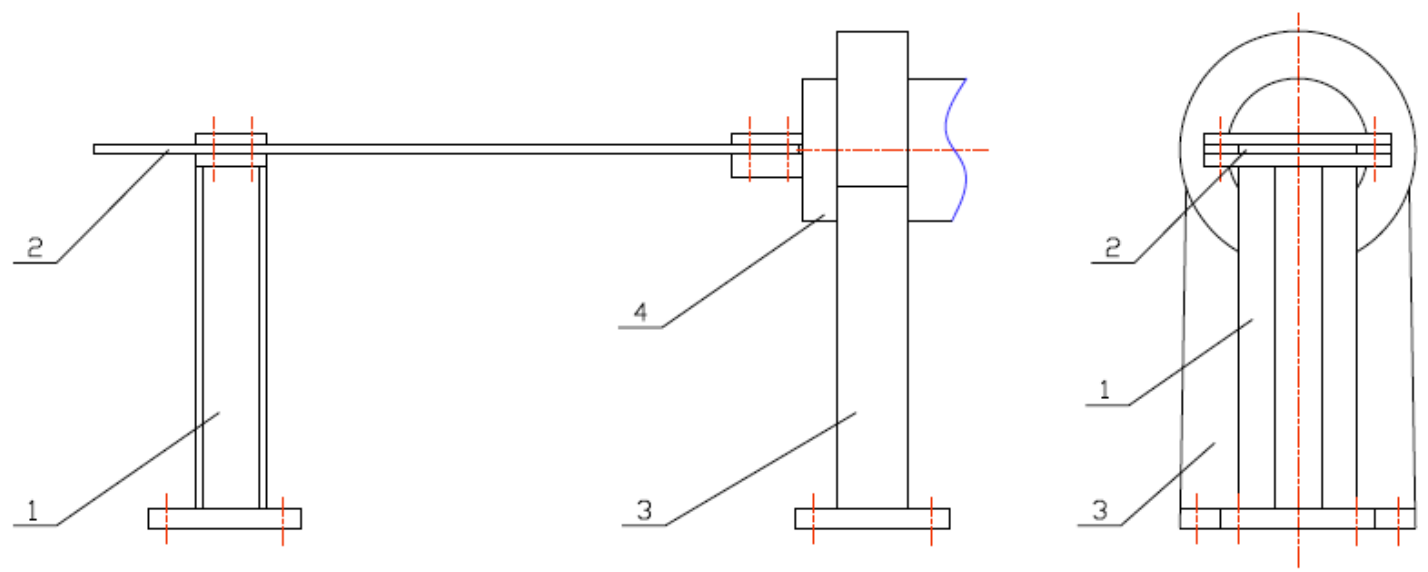

1. Bracket 2. Leaf Spring 3.Torsion Bracket 4.Torsion Shaft (to link to the actuator)

Fig. (8). Principle of the leaf spring torsion loading set.

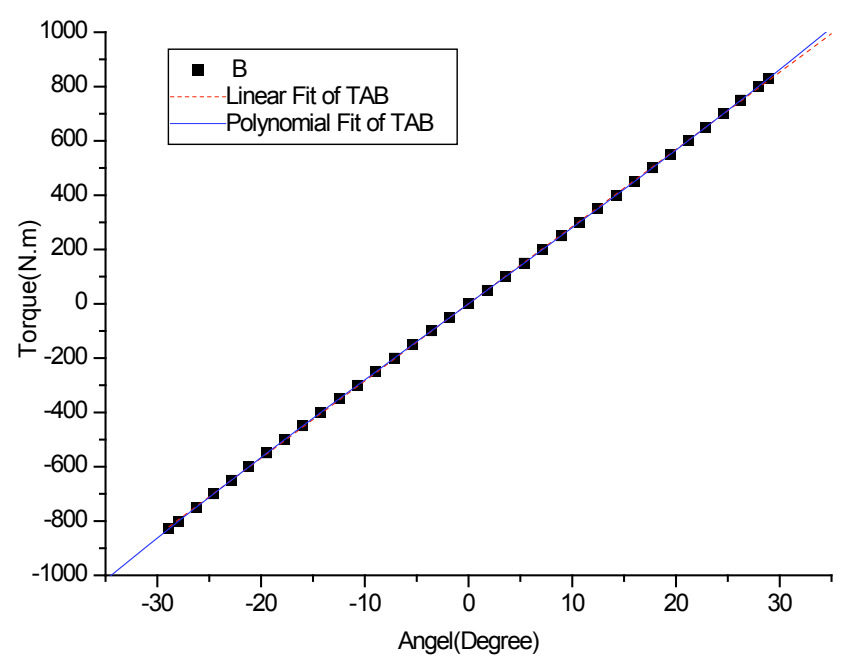

Fig. (9). 1\# leaf spring loading.

Put a leaf spring to the stand and fix two ends to clamp it. One end of the leaf spring is linked to output shaft of a hydraulic motor by torsional shaft. When the output shaft of the hydraulic motor rotates controlled by the pressure and servo valve, the leaf spring will be twisted. The leaf springs used in this experiment are the same as above used in the ANSYS section. Clamped effective length is $781 \mathrm{~mm}$.

In order to show the fitting difference clearly, Figs. (11 and 12) show the enlarged details of the two kinds of fitting. From Figs. (9-12), it can be obtained that experimental results have nothing on with geometry size. When loading to the leaf springs of $1 \#$ and $2 \#$, the relationship of torque and torsional angle is approximately linearly, but not very

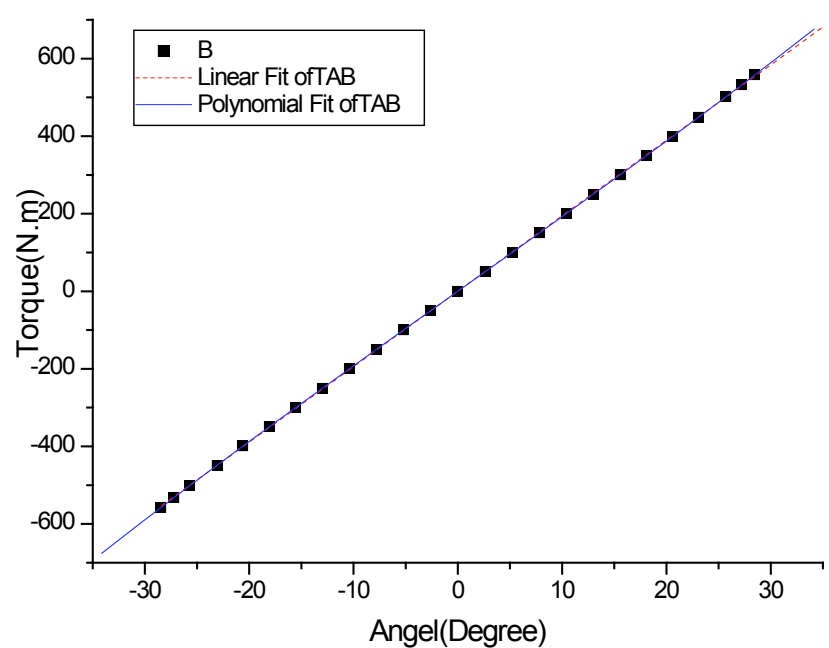

Fig. (10). 2\# leaf spring loading.

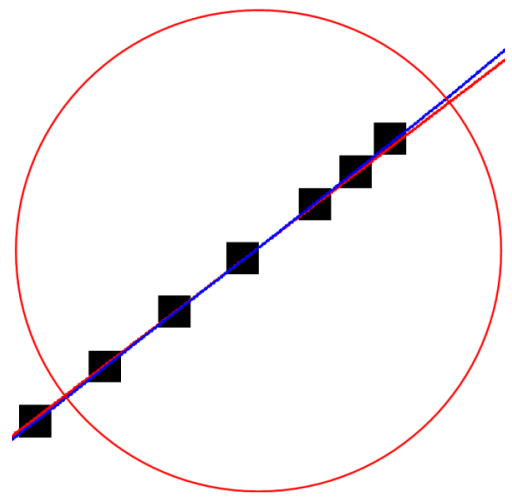

Fig. (11). Local enlarge image of Fig. (9). 
Table 3. Fitting error of 1 \# leaf spring.

\begin{tabular}{|c|c|c|}
\hline & Curve-fit Equation & Error [\%] \\
\hline \hline Linear Fit & $M=28.42394 k$ & 1.2 \\
\hline Polynomial Fit (3-order) & $M=-7.28987 \times 10^{-14}+27.90787 k+1.36213 \times 10^{-16} k^{2}+9.35987 \times 10^{-4} k^{3}$ \\
\hline Precision Improved [\%] & 353 & 0.34 \\
\hline
\end{tabular}

Note: $k$ is the torsion angle $/\left({ }^{\circ}\right), M$ is torque/(N.m).

Table 4. Fitting error of $2 \#$ leaf spring.

\begin{tabular}{|c|c|c|}
\hline & Curve-fit Equation & Error [\%] \\
\hline \hline Linear Fit & $M=19.46061 k$ & 1.3 \\
\hline Polynomial Fit (3-order) & $M=6.6069 \times 10^{-4}+19.15324 k+5.456849 \times 10^{-4} k^{3}$ & 0.43 \\
\hline Precision Improved [\%] & 302 & \\
\hline
\end{tabular}

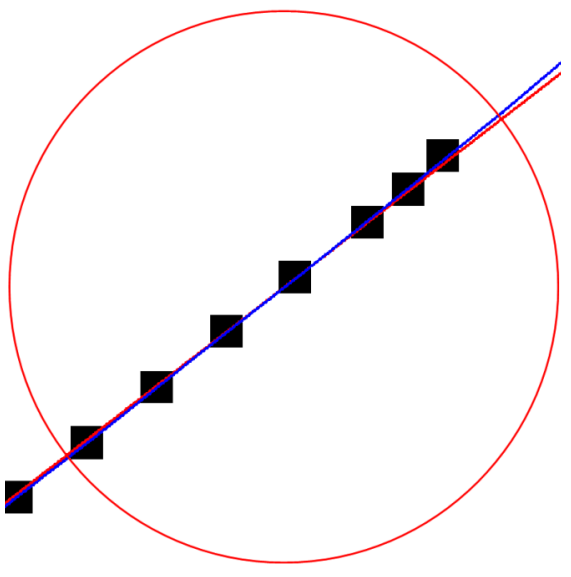

Fig. (12). Local enlarge image of Fig. (10).

strictly, especially with the increasing loading, the errors become large from linear fitting and high order curve fitting. Table 3 and $\mathbf{4}$ give the details of the two kinds of fitting with comparison data.

From Table 3 and 4, it can be seen that the errors between linear fitting and high order curve fitting are very different. The cubic curves have much more accuracy than linear fitting. Accuracy improvement is about 2 orders, which is similar to the FEA results. Therefore uneven material or experimental errors are not the root reasons of these differences. Reference [6] once discussed about this phenomenon. When a part needs high accuracy twisting loading, high order loading curve should be used.

\section{CONCLUSION}

Theoretical analysis shows that different boundary condition does great influence to the relationship of torque and torsional angle, when a rectangular cross section bar twisted with elastic large deformation.

Two kinds of leaf spring with different depth are analyzed using Numerical analysis and experiment. Both results show that, when a member with rectangular cross section twisted with elastic large deformation, the relationship between torque and torsional angle is not strictly linearly. High order curve fitting has more accuracy than linear fitting.

Traditional linear formulas can satisfy general engineering application, but has great error especially elastic large deformation.

So when some member need high accuracy loading such as actuator, the high order curve loading will produce much more accurate loading, this method will do important to mechanical twisting loading.

\section{CONFLICT OF INTEREST}

We declare that this article content has no conflict of interest with other people or organizations that can inappropriately influence our work.

\section{ACKNOWLEDGEMENTS}

The authors would like to acknowledge the support from the Fundamental Research Funds for the Central Universities (YX2014-04).

\section{REFERENCES}

[1] Hayashi, M., Fukuda, M. “Generation of Nanometer Displacement using Reduction Mechanism Consisting of Torsional Leaf Spring Hinges", International Journal Of Precision Engineering And Manufacturing, 13(5), pp.679-684, 2014

[2] Shan Zuhui, Xie Chuanfeng. "Engineering Mechanics", Higher Education press, 2009, 186-188.

[3] Kobelev, V. "Some basic solutions for nonlinear creep", International Journal Of Solids And Structures, 51(19-20), pp.3372-3381, 2014.

[4] Hua, Q., "Studied on the Key Technology of Electro-hydraulic Load Simulator", Ph.D thesis, Beijing University of Aeronautics And Astronautics, 2001.

[5] Wang, S., "Study on the Charactoristics Analysis and Test Technology of the Electro-Hydraulic Actuator", Ph.D thesis, Beijing Institute of Technology, 2004.

[6] Wang, S., and Wang, J., "Dynamic Loading for Missile Actuators", Journal of Beijing Institute of Technology, 27 (3), pp.247-250, 2007. 
[7] Trahair, N.S., "Nonlinear Elastic Nonuniform Torsion", Journal of Structural Engineering Journal of Structural Engineering, 131(7), pp. 1135-1142, 2005.

[8] Young-Jin, Y., "Frictional behavior of automotive leaf spring", Science and Technology, KORUS 2000. Proceedings. The 4th Korea-Russia International Symposium on, 2000, 3, 5-10

[9] Leu, L., and Lee, Y., "Torsion Design Charts for Reinforced Concrete Rectangular Members", Journal of Structural Engineering, 126 (2), pp. 210-218, 2000.

[10] Sugiyama, H., Shabana, A.A., and Omar, M.A., and Loh, W., "Development of nonlinear elastic leaf spring model for multibody ve- hicle systems", Compute Method Appl. M, 195 (50-51), 6925-6941, 2006

[11] Hongwen, L., "Mechanics of Materials", Higher Education Press, pp. 94-97, 2006.

[12] Wei F., "Torsion Leaf Spring Energy Storage Mechanism Design", Equipment Manufacturing Technology, 1, pp.180-182, 2014.

[13] Junho, C., Seonghun, H., and Woosub, L., and Sungchul, K., "A variable stiffness joint using leaf springs for robot manipulators", Robotics and Automation. ICRA '09. IEEE International Conference on, pp. 4363-4368, 2009.

[14] Zhilun, X., "Theory of Elasticity", Higher Education Press, pp.171176, 2006.

(C) Xunwen and Dongmei; Licensee Bentham Open.

This is an open access article licensed under the terms of the Creative Commons Attribution Non-Commercial License (http://creativecommons.org/licenses/by-nc/3.0/) which permits unrestricted, non-commercial use, distribution and reproduction in any medium, provided the work is properly cited. 